holistic and non-punitive approach to the problem. They/we have suffered enough already.

Address supplied

JAN DOYLE

\section{The Russian epidemic}

\section{Dear Sirs}

Having become a news junkie over the momentous events in August it struck me that little has been said about the virulent disease that has singled out the upper echelons of Soviet society. The first the West heard of it was at dawn one Monday when President Gorbachev was reportedly afflicted. This resulted in $\mathbf{7 2}$ hours of isolation from which he emerged slightly disoriented and hesitant. Within hours of the Emergency Committee being formed several members had been taken ill. Many important officials had been unable to oppose the coup due to ill health. Their recovery was rapid once a victor in the ensuing power struggle emerged.

The use of "illness" to dispose of one's enemies plays on the notion of illness being contagious and resulting in stigma. Supporters are then by association equally tainted. Another group appeared to use ill health as a matter of political expediency to avoid conflict and to provide a sanctioned excuse for indecision. The regression to bed and adoption of the sick role would appear to be a powerful defence mechanism and ensure survival.

Crises have a defined anatomy. Those who cannot cope with the situation may retreat to bed denying the fact that something is happening. One's own values play an important part as Gorbachev declared when confronted by the plotters that he would "stand up for my position and will not yield to any blackmail or any pressure and will not take any other decision at all". Once the tide had turned and men were on their way to arrest Pugo, a member of the Emergency Committee, he chose suicide to imprisonment and the humiliation of a trial. His wife also attempted deliberate self harm with him - a testimony to the strength of their values.

Several people died on the streets of Moscow during the coup. The situation is not over yet. The physical symptoms have been taken over by mental indecision, irritability and in some cases grandiosity. Post traumatic stress disorder may affect the out- come in some of the key players. One thing, however, is certain: a coup is not good for one's health.

\section{Middlesex Hospital \\ Wolfson Building \\ London WIN 8AA} VIVIENNE SCHNIEDEN

\section{Logical terminology?}

DeAr Sirs

I understand that the problem of the so-called 'slur' of mental illness is very much in the mind of psychiatrists in this anniversary year.

I consider that the reason for the slur may lie in the very name itself - 'mental illness'. The word 'mental' has disturbing associations for most people. Is it, anyway, a logical name?

In many cases the trouble starts in the 'psyche' and not in the 'mens' primarily - psychiatrists, after all, do not call themselves 'mind experts'. Here is a case of a name mattering very much.

'Psychological illness' would not have the same frightening effect and has a more familiar ring to it.

\section{Pulens Crescent} Patricia M. Smith (Mrs)

\section{Petersfield GU31 4DW}

\section{Teams work}

\section{DeAr Sirs}

Our multidisciplinary community mental health team business meeting was half through, when a wasp flew in through an open window.

It alighted upon an occupational therapist, who had reason to fear anaphylactic shock but calmed the creature by professionally employing an unruffled and immobile posture. As the team psychiatrist, I immediately contributed several theoretical lines of management that could be followed. Simultaneously a member of the social work department invoked an innovative new role for the minutes of the previous meeting and the unfortunate insect was effectively dispatched, to the sound of a community psychiatric nurse empathically stating the case for the minority insect group in the room.

It struck us that we might have seen enacted a microcosm of the working of a multidisciplinary team, and intend to come to some conclusion about this just as soon as we can all find something to agree on.

Name and address supplied 